\title{
Research on the Influence Factors of Fi- nancial Risk Management in Colleges and Universities
}

\author{
Chunhua Li ${ }^{1}$ Zuocai Dai $^{1}$ \\ (1.Zhejiang Normal University Jinhua, Zhejiang Province 321004)
}

\begin{abstract}
:
Firstly, this paper introduces the cause of formation and current status of financial investment risks in colleges and universities. Secondly, it carries out specific analysis on the factors that influence the financial risk management in colleges and universities. Finally, it sums up the enlightenments that the factors exert on the financial risk management in colleges and universities of our country, which has some values on the above management issue.

Key Words : Financial in Colleges and

Universities; Risk; Management;

Factor
\end{abstract}

1. Cause of Formation Analysis on the Financial Risk Management in Colleges and Universities

Financial risks in colleges and universities refer to the uncertain factors in the financial activities which result in the deviation between expected return and financial income, thereby causing financial losses in the end ${ }^{[1-2]}$. Since the higher education institutions are non-profit state institutions, the financial risks faced by them have fundamental difference from those faced by enterprises with profit nature. The financial risks in colleges and universities are mainly manifested as financing risk, operation risk, investment risk and incomplete financial management risk. ${ }^{[3-5]}$. In the financial management activities, the colleges and universi- ties will inevitably be influenced by various recessive crises and dominant factors, or even cause unnecessary financial losses. The main reasons can be concluded as follows:

1.1 Imperfect Financing Channel, Unreasonable Debt Situation

The loan is mainly used to improve the conditions for running schools. Once the infrastructures of colleges and universities are completed, they will belong to the fixed assets of the country. However, the capital recovery cycle used for the construction of fixed assets are usually long. It is hard to repay the principal and interests by the proceeds of fixed assets in short terms. Therefore, the term tuition fees will be used to repay a certain loan as the compensation payment. In this case, the capital for teaching and scientific research is decreased accordingly, which hinders the progress of scientific research. If the loan cannot be handled effectively within a certain period, the financing risk will be gradually increasing.

1.2 The Scale of Financial Expenditure Increases While the Income Mode is Single and Insufficient

The expenditure used for education shows an increasing tendency each year. As the higher education gains an increasing attention from the whole society, it has transformed from the elite education in the forties and fifties to the current public education. The internal competi- 
tions among colleges and universities are intensifying. In order to enhance their reputations and strengthen the influence and competitiveness among schools, colleges and universities increase investment to carry out campus infrastructure construction. The cost for contraction is greatly increased while the income is slight.

\subsection{Blindly Investing in Hardware Fa- cility Construction While Neglecting Software Facility Construction Results in Resource Waste}

In the process of adding teaching equipment, building laboratory and constructing a new campus, the phenomena of capital waste and lack of scientific and rational proof are serious. Especially in the process of new campus construction, due to the lack of discreet pre-evaluation and the estimation of investment return, the debt pressure increases under the situation of extended turnover cycle of floating capital.

\subsection{Backward Financial Management System, Weak Internal Control}

Although the undertaking of higher education realizes development by leaps and bounds under the condition of China's rapid economic growth, the financial management systems of colleges and universities have not yet kept pace with development of schools. There are still some defects existed in the system, which is separated from the actual education development. The research on the management theories and methods of financial risks in colleges and universities indiscriminately imitate those in enterprises, without practically and realistically considering the actual situation of the accounts in schools. In this case, the reflect of the financial risks in schools is not accurate. Therefore, it is hard to play a defensive and warning effect on their financial risks.

Colleges and universities usually center on the financial risk management among all the risk and economic managements ${ }^{[6]}$. The scale of higher education expands unprecedentedly at present and the number of enrollment increases rapidly. The percentage of public education is in rapid expansion and the achievements for running schools continue to emerge. However, the rapid development is accompanied by crisis. ${ }^{[7]}$ On one hand, it will cause severe fluctuations in the financial capital flow; on the other hand, colleges and universities have decided to invest large sums of money to improve conditions for running schools. Therefore, they ask for loans to operate schools in large scales, which reveals the financial crisis of schools and means that the financial management in colleges and universities transforms from the times of low risk management to the times of risky or even high risk management. Therefore, the research on the financial risk management in colleges and universities is a pressing task.

\section{Countermeasure Analysis on Finan- cial Risk Management}

Financial risk management in colleges and universities is composed of internal environment, goal setting, event identification, risk assessment, risk response, financial activities control, information processing and communication, financial control and other factors. In dealing with all kinds of financial activities, colleges and universities should grasp the right reason of financial risk and adopt the corresponding measures to deal with it so as to better alleviate the financial risk and improve the effectiveness of financial management.

Withe the rapid development of China's market economy and the continuous in-depth revolution of higher education system, the financial management in schools of higher education will inevita- 
bly face more demanding challenges. And the reasons and factors that influence the risk management will also change with the rapid development of colleges and universities.

\subsection{Assets of Colleges and Universities- -Large in Amount and Weak in Liquidity}

The operation characteristics determine the substantive feature of the assets. The assets in colleges and universities have the significant characteristic of large in amount, which accounts for high percentage in total assets. Due to this characteristic, the liquidity and cashability of assets is weak in actual financial activity. The receivable amount and temporary payment, the loans made by schools, the school capitals used for infrastructure construction, and the annual budget which is insufficient to make up for the expenditure are the main reasons for weak liquidity of assets ; The assets which have formed a part of expenditure become the fixed assets of schools after delivery, which are embodied as capital source and occupation. In this case, the gradual accumulation of fixed assets increases; the cashability of this part of assets is weakening, which weakens the repaying ability for due debts of colleges and universities.

\subsection{Short Cycle and Single Mode for Debt Repayment}

The debts in colleges and universities are composed of payable, temporary deposit, other payables, payable taxes, escrow payment and borrowing payment while those in financial institutions are mainly composed of borrowing payment and foreign government loans guaranteed by the government. The repayment period for capitals borrowed from financial institutions or enterprises is usually 1 to 6 years. And the interests should be paid in a quarterly manner and the principal needs to be repaid in accordance with rel- evant contracts or agreements. The government special investment or discount interest fund, extra budgetary funds and other self-owned capital constitute the source of repaying capital with interest in installment. When the government special investment or discount interest fund is less, it will affect the financial operation in colleges and universities to a certain extent, or even sometimes it will delay in payment of principal and interest.

\subsection{Cash Income Has Low Peak Period and High Peak Period}

Financial allocation and extra budgetary funds are the blood and power for the normal operation of colleges and universities. Financial allocation includes the basic expenditure and related special expenditure. The basic expenditure is usually allocated to the zero balance account of schools on a monthly basis while the special expenditure is allocated to the school accounts with the school budgets, the time of which mainly concentrates on the second half of the year; the annual balance fund and the balance amount in zero balance account of financial cancellation can only be used after verification and allocation in the next year. If the enrollment is shrinking and declining within a period of time, a considerable part of the funds cannot realize expectation. The repayment of principal and interest becomes more difficult and crisis will appear in financial operation.

\subsection{Disposal of Public Welfare Is Diffi- cult Due to Its State-owned Na- ture}

School assets are the assets with public, state-owned and fixed nature, which cannot be used for mortgage and are difficult to handle. The disposal of school assets should be in accordance with relevant management regulations regarding state-owned assets. Moreover, under the premise of strict examination and approval procedures, the assets 
should not be disposed without the approval of relevant departments. Therefore, the relevant school assets should be used for the repayment of due debts, which results in the limited cashability of various kinds of assets.

In general, all of the factors above reflect the cashability, cash flow ability and debt repayment ability of colleges and universities from different angles and aspects. If there is no enough floating capital for schools to ensure the repayment of due debts and interests after debt financing, financial risks will occur. The potential influence factors will cause the deterioration of financial situation and thus evolve into a financial crisis.

\section{Enlightenment about the Financial Risk Management in Schools of Higher Education}

The debt scale expansion is generally manifested as the accumulation of school assets, expansion of school scale, and promotion of school level and reputation; and meanwhile it is manifested as debt in huge amount, constant compression of operation fees, and influence on teaching order. Therefore, financial risk management in colleges and universities arouses great attention of the founders and relevant government departments, main creditors, main beneficiaries, and the society. It is a long-term and arduous task for defusing the financial risks in colleges and universities.

\subsection{Government Should Increase Fi- nancial Support to Schools and Give Appropriate Development Require- ment}

The sustained debt growth brings the rapid development to schools and promotes the prosperity of the cause of higher education at the same time. The development construction of schools should be completed in a relatively short period of time. But the constructive programs will bring long-term right of use for schools. During the whole period of use, the funds invested in the program generally can be recovered in full and pretty good profitability can be obtained. The construction funds generally come from the short-term or medium-term loans of banks. Since the principal and interest should be repaid on schedule, the debt scale of some schools is far beyond its repayment ability. Therefore, they can only borrow loan from other places to repay the original debt. The vicious cycle like this results in the increasingly large scale of debts for schools. The cause of higher education is operated by colleges and universities, which is also a public service cause. The education funds should of course be borne by the state government. Therefore, in order to ensure the effective operation of the cause of higher education in high quality and reduce the debt burden of the construction programs, the government should give fiscal interest subsidy and targeted fiscal subsidy in installment. The schools of higher education and the government should bear the debt for construction program together. If the government can take measures to transform the short and medium-term loans into long-term loans, it can effectively alleviate the burden of short-term debt faced by the schools. In this way, it can greatly provide the schools with financial expenses for construction programs. Under appropriate circumstances, schools can carry out construction based on funds obtained from bank loans or enterprise financing. The profits obtained therefrom will be used to enhance the strength of the school and to improve the teaching quality, which can alleviate the pressure caused by the government's public investment. From the short-term consideration, the increase of investment in colleges and universities will enlarge the fiscal burden of the government in some level; 
from the long-term consideration, the increase of the fiscal subsidy to schools does not enlarge the public pressure of the government. Therefore, the financial support from the government is the key to solve the financial risks of colleges and universities.

\subsection{Colleges And Universities Try to Guarantee the Strength of Repaying Capital with Interest}

From the characteristics of our colleges and universities, as the main undertakers of the debts, the main members for repaying debts are still colleges and universities. It is proper that the government gives a certain subsidies. It lacks rationality to completely rely on the government to repay the debts. If the capability of the government is limited, colleges and universities should proceed from their own, set up financial risk consciousness and establish risk early warning mechanism; Colleges and universities can use appropriate methods to ensure the teaching quality and reduce the operation cost at the same time; meanwhile, combined with their own strengths, schools can carry out relevant communication with relevant lending banks, and obtain the understanding from the bank in terms of time and amount under the circumstance of payment in installment of interest so as to establish a reasonable risk control and financial early warning system; schools should rationally arrange the fund use to ensure the stable cash flow, try to avoid the debt overlapping situation, and try to prevent the occurrence of financial risks.

\subsection{Improve Accounting System and Formulating Effective Accounting Sys- tem Which Can Completely Reflect Fi- nancial Status}

The main mechanism of the accounting system in colleges and universities of our country: it places emphasis on the reflection and analysis of implementation situation and neglects cost accounting and benefit calculation; it places emphasis on business financial and infrastructure accounting and neglects overall accounting; it places emphasis on the reflection of historical value of assets and neglects the reflection of net value of assets; it places emphasis on explicit debt reflection and neglects implicit debt reflection, etc. The characteristic of the current college accounting system can only roughly reflect the debt status to a great extent while it cannot reflect the educational cost capital and educational cost capital per capita accurately. To some extent, it is by no means able to reflect the educational cost of schools caused by debt. Therefore, the accounting system needs further improvement. It can accurately reflect the school accounting system of revenue and expenditure by accounting on the accrual basis. On the basis of the realizing school cost, reasonable determination of the allocation mechanism of cost and interest can provide a scientific basis for the government to accurately determine the financial allocation and collection standards for charges, to examine and approve the investment on construction programs, and to carry out benefit assessment on school operation; it can provide the lending institutions with scientific basis to objectively evaluate the financial risk, determine the reasonable loan amount, and correctly analyze the profit of investment program; it can provide the society of all walks of life with basis for the effective use of the funds of colleges and universities, and for the supervision of talent cultivation and teaching quality.

\subsection{Improve Appraisal Indicators of Department in Charge, Establish Per- fect Appraisal Indicators}

The current appraisal indicators in ordinary schools of higher education have relevant loopholes, which results in certain blindness in the scale of relevant construction programs. Under the current accounting system which is used to re- 
flect the budget implementation status, the guidance for the schools is confusing in some level in terms of some short and medium-term investments, such as the purchase of equipment, major and subject construction, laboratory construction, basic construction, infrastructure repair, etc, which is hard for schools to formulate relevant policies under clear conditions. Blind implementation of relevant infrastructure and related investment will increase the financial crisis for colleges and universities. Therefore, in the process of formulating all kinds of appraisal indicators, department in charge of higher education should treat sustained and healthy development of schools as target, consider the education and teaching quality as orientation, and take the benefit improvement of running schools as basis to guide the development and construction of colleges and universities.

To properly deal with the problems of financial crisis and debt, the government should enlarge the financial support strength to support the debts of the schools. And meanwhile the government should raise some proper requirements for development on schools to broaden the sources of income and economize on expenditures to ensure the repayment of interests of debts and raise public credibility. It also needs attention, understanding and support from the whole society. Measures from a variety of channels and methods should be taken to alleviate and solve the debt problem and financial risk of schools so as to promote the stable, healthy and vigorous development of colleges and universities.

\section{Reference}

[1] Xiaobing Wu, "Study on comprehensive risk management of higher school, " Proc. Xiamen: Xiamen Universitymaster thesis, pp. 123-189, 2006.

[2] Ting Hua, Xiangyun $\mathrm{Xu}$, “The reform of

University Management : build a comprehensive risk management system,

Proc. Journal of Jiangxi Agricultural

University, pp. 130-132, 2009.

[3] lei Zhang, Bowei Zhang, "The connotation of theory of Chinase huge collection of university and management innovation," Proc. Journal of education science, pp. 46-47, 2005.

[4] Birnbaum, Yaqing Mao, "The management style of higher education," Proc. beijing:Beijing normal university press, pp. 67-98, 2008.

[5] Weihua Fang, "The hierarchy system diversity and system analysis," Proc. Sociological study, pp. 127-130, 2005.

[6] Yingluo Luo, Xiaoyong Li, "The influence factors in the process of implementation of risk assessment," Proc. computer security, pp. 59-60, 2004.

[1] [7] Lingling Ma, "From risk management, how to strengthen the enterprise internal control, "Proc. Inner Mongolia science and technology and economy, pp. 50-51, 2005. 